\title{
The effects of posterior cruciate ligament rupture on the biomechanical and histological characteristics of the medial collateral ligament: an animal study
}

Wen-qing Xie ${ }^{1} \mathbb{D}$, Miao He${ }^{1}$, Yu-qiong He$e^{1}$, Deng-jie $\mathrm{Yu}^{1}$, Hong-fu Jin ${ }^{1}$, Fang $\mathrm{Yu}^{1,2^{*}}$ and $\mathrm{Yu}$-sheng $\mathrm{Li}^{1,2^{*}}$

\begin{abstract}
Background: To investigate the effect of complete rupture of the posterior cruciate ligament (PCL) on the biomechanics and histology of the medial collateral ligament (MCL).

Materials and methods: Seventy-two male rabbits were randomly divided into two groups: the ruptured group was treated with complete $P C L$ amputation, while the intact group was only subjected to $P C L$ exposure without amputation. Eighteen rabbits were randomly sacrificed at 8, 16, 24, and 40 weeks after the operation, and their specimens were processed for mechanical tensile testing, nano-indentation experiments, hematoxylin-eosin (HE) staining, and picrosirius-polarization staining.

Results: There was no significant difference in the length and maximum displacement of the MCL between the ruptured group and the intact group at each time point. The maximum load of the ruptured group was significantly smaller than that of the intact group at $40 \mathrm{~W}$. The elastic modulus and micro-hardness of the ruptured group increased significantly at $24 \mathrm{~W}$ and decreased significantly at $40 \mathrm{~W}$. At $16 \mathrm{~W}$ and $24 \mathrm{~W}$ after PCL rupture, the number of type I collagen fibers and type III collagen fibers in the $\mathrm{MCL}$ of the ruptured group was significantly increased compared with that of the intact group. While the type I collagen fibers of the ruptured group were significantly decreased compared with the intact group at $40 \mathrm{~W}$, there was no significant difference in type III collagen fibers between the ruptured group and the intact group.
\end{abstract}

Conclusion: PCL rupture has no significant effect on the mechanical and histological properties of MCL in a short period of time under physiological loading, but the histological and mechanical properties of MCL decrease with time.

Keywords: PCL rupture, MCL, Collagen fiber, Elastic modulus, Micro-hardness

*Correspondence: yufang_xy@126.com; liyusheng@csu.edu.cn

'Department of Orthopaedics, Xiangya Hospital, Central South University, 87 Xiangya Road, Changsha 410008, Hunan, China

Full list of author information is available at the end of the article

C C The Author(s). 2021 Open Access This article is licensed under a Creative Commons Attribution 4.0 International License, which permits use, sharing, adaptation, distribution and reproduction in any medium or format, as long as you give appropriate credit to the original author(s) and the source, provide a link to the Creative Commons licence, and indicate if changes were made. The images or other third party material in this article are included in the article's Creative Commons licence, unless indicated otherwise in a credit line to the material. If material is not included in the article's Creative Commons licence and your intended use is not permitted by statutory regulation or exceeds the permitted use, you will need to obtain permission directly from the copyright holder. To view a copy of this licence, visit http://creativecommons.org/licenses/by/4.0/. The Creative Commons Public Domain Dedication waiver (http://creativecommons.org/publicdomain/zero/1.0/) applies to the data made available in this article, unless otherwise stated in a credit line to the data. 


\section{Introduction}

The PCL is an indispensable ligament for maintaining the stability of the knee joint. This ligament is the most powerful in the knee joint and is connected to the femur and tibia in the form of a hinge $[1,2]$. The PCL corresponds to the anterior cruciate ligament (ACL), which mainly prevents the tibia from moving backward relative to the femur. It has been reported that the average age of PCL injuries is $27.5 \pm 9.9$ years, of which traffic accidents (45\%) and sports injuries (40\%) are the most common causes of injury [3]. However, the latest epidemiological results show that physical activity $(38.8 \%)$ is the main factor of PCL injury, followed by traffic injury (35\%) [4]. Any force that causes PCL stress can cause PCL injury, and its injury mechanism $[5,6]$ is usually the excessive application of force from front to back to the tibia, which often occurs in the flexion position.

According to the degree of relaxation, PCL injury can be divided into $3^{\circ}$. At present, most scholars have reached a consensus on degree I-II injuries, that is, conservative treatment [7-9]. However, the treatment of degree III injury is still controversial. Some scholars believe that timely surgery can delay the occurrence of osteoarthritis (OA). Some people think that surgical reconstruction may not be able to prevent the occurrence of OA. However, it is still considered that surgical reconstruction should be performed when the PCL is in grade III injury [10, 11]. Unfortunately, most of the current treatment options for PCL injury are controversial. There is no effective and rigorous randomized controlled trial to compare various treatment methods or complete and rigorous guidelines for PCL injury to guide clinicians.

Because PCL rupture is mostly caused by strong violence, it often combines with other structures inside and outside the joint. Schulz et al. [3] found that only $47 \%$ of patients had simple PCL injuries. Petrigliano et al. [12] reported that $96.5 \%$ of PCL injuries were associated with other ligament injuries, including anterior cruciate ligament, lateral collateral ligament, or lateral stable structure injury. The biomechanical or histological effects of PCL rupture on the medial femoral condyle [13], the lateral femoral condyle [14], the medical tibial plateau [15], and the medical meniscus [16] have been studied by scholars. However, the effect of PCL rupture on the MCL is still lacking, and most of the existing studies focus on the ACL.

Therefore, in this study, mechanical tensile testing and nano-indentation technology were used to study the MCL after PCL rupture. At the same time, the change in the mechanical properties of the ligament and the relationship between them were discussed at the micro- and macro-levels. In addition, the histomorphology of MCL, the quantity of type I and type III collagen, and the ratio of type I and type III collagen were observed by histological methods.

\section{Materials and methods \\ Materials \\ Experimental animals}

Seventy-two 2-month-old male rabbits with an average body weight of $2.5 \pm 0.4 \mathrm{~kg}$ were provided by the experimental animal Department of Xiangya Hospital, Central South University. The animal experiments were carried out in accordance with relevant guidelines and regulations and were approved by the medical ethics committee of Xiangya Hospital of Central South University (No: 201908799). The adaptation before intervention was as follows: feeding environment for 7 days; ambient temperature $(21 \pm 3){ }^{\circ} \mathrm{C}$; relative humidity $(55 \pm 5) \%$, light-dark cycle of $24 \mathrm{~h}$ and normal circadian rhythm. The diet and diarrhea of the animals were observed every day.

\section{Main experimental equipment}

An MTS 858 system (provided by the key Mechanics Laboratory of the Ministry of Education, School of Materials Science and Engineering, Central South University, manufactured by MTS company, USA), an ultra-nanohardness tester (unht), and an OPX system (provided by the National Key Laboratory of powder metallurgy of Central South University and manufactured by CSM instrument company of Switzerland) were used.

\section{Main reagents}

Pentobarbital sodium (subpackaged by the Shanghai Chemical Reagent Company of China Pharmaceutical Group) was prepared into a $3 \%(0.03 \mathrm{mg} / \mathrm{kg})$ solution for standby, and penicillin powder injection for injection (North China Pharmaceutical Co., Ltd.) and 0.1\% sirius red picric acid staining solution (Beijing Hyde Biological Preparation Co., Ltd.) were also purchased.

\section{Methods \\ Experimental group}

Seventy-two rabbits were randomly divided into an experimental group and a control group. The observation time points were $8 \mathrm{~W}, 16 \mathrm{~W}, 24 \mathrm{~W}$, and $40 \mathrm{~W}$ after modeling. Eighteen rabbits were randomly sacrificed at each time point for biomechanics and histological study. Six of them were subjected to mechanical tensile testing, six were subjected to nano-indentation testing, and the other six were subjected to histological analysis. A total of 48 rabbits were studied for biomechanics, and 24 rabbits were studied for histology. 


\section{Model preparation}

The method used was the same as that in our previous study $[15,16]$. In short, rabbits were injected with $3 \%$ pentobarbital solution $(0.03 \mathrm{mg} / \mathrm{kg})$ through the ear vein. After anaesthesia was achieved, the rabbits were fixed in the supine position. The stability of the knee joint was checked by anterior and posterior drawer and medial and lateral turnover stress tests. Skin preparation, disinfection, and towel spreading were carried out in the bilateral knee joint area. In the experimental group, the skin, subcutaneous tissue, and medial patellar retinaculum were incised layer by layer. The patella was dislocated laterally, and the PCL was exposed and completely removed. The intraarticular tissues were protected during the operation, and hemostasis was carefully performed. After washing with normal saline and suturing layer by layer, a gauze bandage was used to bandage without fixation. The operation procedure of the control group was the same as that of the experimental group, but the PCL was only exposed without being removed. After the operation, the rabbits were fed in cages and had free drinking water. The diet, diarrhea, and wound infection of the rabbits were observed every day. Penicillin $80 \times 104$ U was intramuscularly injected once a day for 3 days. The rabbits were killed by air embolism at each time point, and the specimens were collected.

\section{Biomechanical observation indexes}

The lateral collateral ligament, anterior PCL, and meniscus of the rabbit knee joint were removed, only the femur MCL tibia complex (FMTC) was reserved, and approximately $6 \mathrm{~cm}$ of the tibia and femur was reserved. Observations: (1) the length of the MCL was as follows: the initial length of the MCL of 48 experimental rabbits was measured with a Vernier caliper (the measurement accuracy was $0.01 \mathrm{~mm}$ ), and the average value was obtained by measuring 3 times; (2) the mechanical tensile test was performed as follows: the method used in the previous study was the same [17]. In short, the two ends of the FMTC of 24 rabbits were fixed with a homemade tensile test fixture and then placed on a dynamic tension torsion combined testing machine to make the longitudinal axis of the ligament consistent with the direction of the tensile force line. During the stretching process, a static preload of $0.5 \mathrm{~N}$ was applied for 5 minutes, and then, the maximum load was loaded and unloaded at a rate of $5 \mathrm{~mm} / \mathrm{min}$ at $0.5 \%$ of the maximum load 20 times. Then, the maximum load tensile test was conducted at $5 \mathrm{~mm} / \mathrm{min}$. The maximum loading load and displacement of the MCL were recorded. (3) The nanoindentation experiment was conducted as follows: the method used was the same as that described in a previous study [18]. In short, the MCL specimens of 24 experimental rabbits were cut parallel to the longitudinal axis with a frozen microtome, placed on a homemade slide, and fixed on the stage of the ultra-nanoindentation instrument. The smooth surface area was manually searched under an optical microscope at 4000 times magnification, the depth was measured with a diamond probe, and the indentation images were collected. Under constant strain rate loading mode, the maximum load was $500 \mu \mathrm{N}$, the loading and unloading speed was $50 \mu \mathrm{N} / \mathrm{s}$, and the holding and unloading times were both $10 \mathrm{~s}$. Five points in the middle area of the sample were selected for the indentation test, and the distance between the points was more than 20 times the indentation diameter. The load depth curve was recorded, and the micro-hardness and elastic modulus were obtained from the unloading stage.

\section{Histological observation index}

The MCL specimens of 24 rabbits were observed as follows: (1) HE staining: the MCL specimens were washed with normal saline, fixed in $4 \%$ paraformaldehyde solution for $24 \mathrm{~h}$, decalcified, dehydrated with gradient ethanol, cleared with xylene, embedded in paraffin, and sliced continuously at a thickness of $3 \mu \mathrm{m}$. The distribution and arrangement of collagen were observed under a microscope after HE staining. (2) Picrosirius-polarization staining: routine section, dewaxing, and dehydration of specimens were performed. Then, the cells were soaked in Sirius red picric acid staining solution for $1 \mathrm{~h}$, dyed again, cleared, and sealed after washing. A section was taken from each specimen, and the distribution and shape of type I and type III collagen fibers were observed under a polarization microscope. Five fields of vision were randomly selected from each slice at 400 times magnification and photographed at the same exposure. The relative total area of type I collagen fibers (red and yellow) and type III collagen fibers (green) and the ratio of type I/III collagen fibers was obtained by measuring the red, yellow, and green areas with Image Proplus 6.0 image analysis software. The unit of the relative area of collagen fiber was pixels.

\section{Statistical analysis}

SPSS 21.0 for Windows statistical software was used for statistical analysis. The data are expressed as the mean \pm standard deviation (SD). A $t$ test was used to compare the mean of two samples. $P<0.05$ was considered significant.

\section{Results}

Comparison of MCL length

At $8 \mathrm{~W}, 16 \mathrm{~W}, 24 \mathrm{~W}$, and $40 \mathrm{~W}$ after PCL rupture of the knee joint, the MCL of the experimental group and the control group lengthened gradually with time, the 
length of the MCL in the experimental group was greater than that in the control group at each time point, and the difference was not significant. $P>0.05$ indicated that there was no significant difference in MCL length between the experimental group and the control group at each time point.

Maximum load and maximum displacement of the $M C L$ At $8 \mathrm{~W}, 16 \mathrm{~W}$, and $24 \mathrm{~W}$, the maximum load of the MCL in the experimental group and the control group increased gradually. At $40 \mathrm{~W}$, the MCL load of the control group remained unchanged, but the MCL load of the experimental group decreased. At $8 \mathrm{~W}, 16 \mathrm{~W}$, and $24 \mathrm{~W}$, the maximum load of the MCL in the experimental group was greater than that in the control group, and the difference gradually decreased with the extension of time. There was no significant difference between the experimental group and the control group at each time point $(P>0.05)$. The maximum load of the experimental group at $40 \mathrm{~W}$ was smaller than that of the control group, and the difference was significant $(P<0.05)$. The results of the maximum load of the knee MCL are shown in Table 1.

The maximum displacements of the experimental group and the control group at each time point are shown in Table 2. The maximum displacement of the experimental group at $8 \mathrm{~W}, 16 \mathrm{~W}, 24 \mathrm{~W}$, and $40 \mathrm{~W}$ was greater than that of the control group. The $t$ test for pairwise comparison of the experimental group and the control group at each time point was performed, and the results were all $P>0.05$. Therefore, it was considered that there was no significant difference in the maximum displacement between the experimental group and the control group at each time point.

\section{Modulus of elasticity of the MCL}

The elastic modulus of the MCL of the experimental group and the control group at each time point after PCL rupture of the knee joint are shown in Table 3. The nano-indentation test of the eight groups of samples showed that the modulus of elasticity of the control group was the smallest at $8 \mathrm{~W}$, which was $3.116 \pm 0.267$ $\mathrm{GPa}$, while that of the experimental group was the largest at $24 \mathrm{w}$, which was $3.440 \pm 0.277 \mathrm{GPa}$. There was no significant difference in the elastic modulus between the

Table 1 Maximum load of $M C L$ after $P C L$ rupture of rabbit knee joint $(\bar{x} \pm s$, unit: $N)$

\begin{tabular}{llll}
\hline Time point & Experimental group & Control group & $P$ \\
\hline 8W & $63.86 \pm 4.53$ & $56.79 \pm 3.22$ & $>0.05$ \\
16W & $68.30 \pm 4.29$ & $62.24 \pm 4.69$ & $>0.05$ \\
24W & $69.02 \pm 5.03$ & $66.22 \pm 3.45$ & $>0.05$ \\
40W & $60.48 \pm 7.00$ & $66.22 \pm 3.45$ & $<0.05$ \\
\hline
\end{tabular}

Table 2 Maximum displacement of MCL after PCL rupture of rabbit knee joint ( $\bar{x} \pm s$, unit: $m m)$

\begin{tabular}{llll}
\hline Time point & Experimental group & Control group & $\boldsymbol{P}$ \\
\hline $8 \mathrm{~W}$ & $3.39 \pm 0.15$ & $3.31 \pm 0.16$ & $>0.05$ \\
$16 \mathrm{~W}$ & $3.43 \pm 0.18$ & $3.38 \pm 0.16$ & $>0.05$ \\
24W & $3.56 \pm 0.16$ & $3.34 \pm 0.09$ & $>0.05$ \\
$40 \mathrm{~W}$ & $3.54 \pm 0.22$ & $3.41 \pm 0.17$ & $>0.05$ \\
\hline
\end{tabular}

experimental groups and the control group at $8 \mathrm{w}$ and $16 \mathrm{w}(P>0.05)$, while there was a significant difference in the elastic modulus between the experimental groups and the control group at $24 \mathrm{~W}$ and $40 \mathrm{~W}(P<0.05)$. The elastic modulus of the MCL in the experimental group and the control group increased gradually at $8 \mathrm{~W}, 16 \mathrm{~W}$, and $24 \mathrm{~W}$ and remained basically the same as that in the control group at $40 \mathrm{~W}$, but the elastic modulus of the MCL in the experimental group decreased. The elastic modulus of the MCL in the experimental group was greater than that in the control group at $8 \mathrm{~W}, 16 \mathrm{~W}$, and $24 \mathrm{~W}$, while the value in the $40 \mathrm{~W}$ control group was greater than that in the experimental group.

\section{Nano-indentation micro-hardness of the MCL}

The MCL micro-hardness of the experimental group and the control group at each time point is shown in Table 3. A nano-indentation test was performed on eight groups of samples. The results showed $P>0.05$ between the two groups at $8 \mathrm{~W}$ and $16 \mathrm{~W}$ and $P=0.040$ at $24 \mathrm{~W}$. Therefore, it was considered that the MCL microhardness of the experimental group at $24 \mathrm{~W}$ was significantly greater than that of the control group. $P<0.05$ indicated that the MCL micro-hardness of the experimental group at $40 \mathrm{~W}$ was significantly lower than that of the control group. The MCL micro-hardness of the experimental group and the control group increased gradually at $8 \mathrm{~W}, 16 \mathrm{~W}$, and $24 \mathrm{~W}$ and decreased at 40 $\mathrm{W}$, while the micro-hardness of the control group increased with the passage of time at all time points. The MCL micro-hardness of the experimental group was greater than that of the control group at $8 \mathrm{~W}, 16 \mathrm{~W}$, and $24 \mathrm{~W}$, while the MCL micro-hardness of the $40 \mathrm{~W}$ experimental group was lower than that of the control group.

\section{HE staining}

There was no significant difference in the MCL between the experimental group and the control group at $8 \mathrm{~W}$, $16 \mathrm{~W}$, and $24 \mathrm{~W}$ after PCL rupture. At $40 \mathrm{~W}$, some round and oval and a small number of spindle cells were observed in the experimental group. The cells were arranged in a vertical line. The color of the cells was dark, 
Table 3 Elastic modulus and micro-hardness of MCL after PCL rupture in rabbit knee joints ( $\bar{x} \pm s$, unit: GPa)

\begin{tabular}{|c|c|c|c|c|}
\hline \multirow{2}{*}{$\begin{array}{l}\text { Time } \\
\text { point }\end{array}$} & \multicolumn{2}{|l|}{ Elastic modulus } & \multicolumn{2}{|l|}{ Micro-hardness } \\
\hline & Experimental group & Control group & Experimental group & Control group \\
\hline $8 W$ & $3.154 \pm 0.450$ & $3.116 \pm 0.267$ & $0.126 \pm 0.018$ & $0.124 \pm 0.016$ \\
\hline $16 \mathrm{~W}$ & $3.305 \pm 0.274$ & $3.213 \pm 0.296$ & $0.141 \pm 0.012$ & $0.130 \pm 0.020$ \\
\hline $24 \mathrm{~W}$ & $3.440 \pm 0.277$ & $3.258 \pm 0.291^{*}$ & $0.152 \pm 0.012$ & $0.140 \pm 0.016^{*}$ \\
\hline $40 \mathrm{~W}$ & $3.175 \pm 0.318$ & $3.288 \pm 0.323^{*}$ & $0.314 \pm 0.025$ & $0.145 \pm 0.023^{*}$ \\
\hline
\end{tabular}

${ }^{*} P<0.05$

the size was different, and the distribution was uneven. The collagen fibers outside the cells were small, sparse, and orderly arranged, as shown in Fig. 1a. In the control group, some spindle cells were observed, which were arranged vertically. The color of the cells was dark, the size was different, and the distribution was uneven. The collagen fibers outside the cells were dense and arranged in an orderly manner, as shown in Fig. 1b.

\section{Picrosirius-polarization staining}

Under a polarization microscope, there was no significant difference in the MCL between the experimental group and the control group at $8 \mathrm{~W}, 16 \mathrm{~W}$, and $24 \mathrm{~W}$ after PCL rupture. At $40 \mathrm{~W}$, the collagen fibers in the experimental group were obviously loose, the local arrangement was not neat, and most of them were in the same direction. Type III collagen fibers were distributed
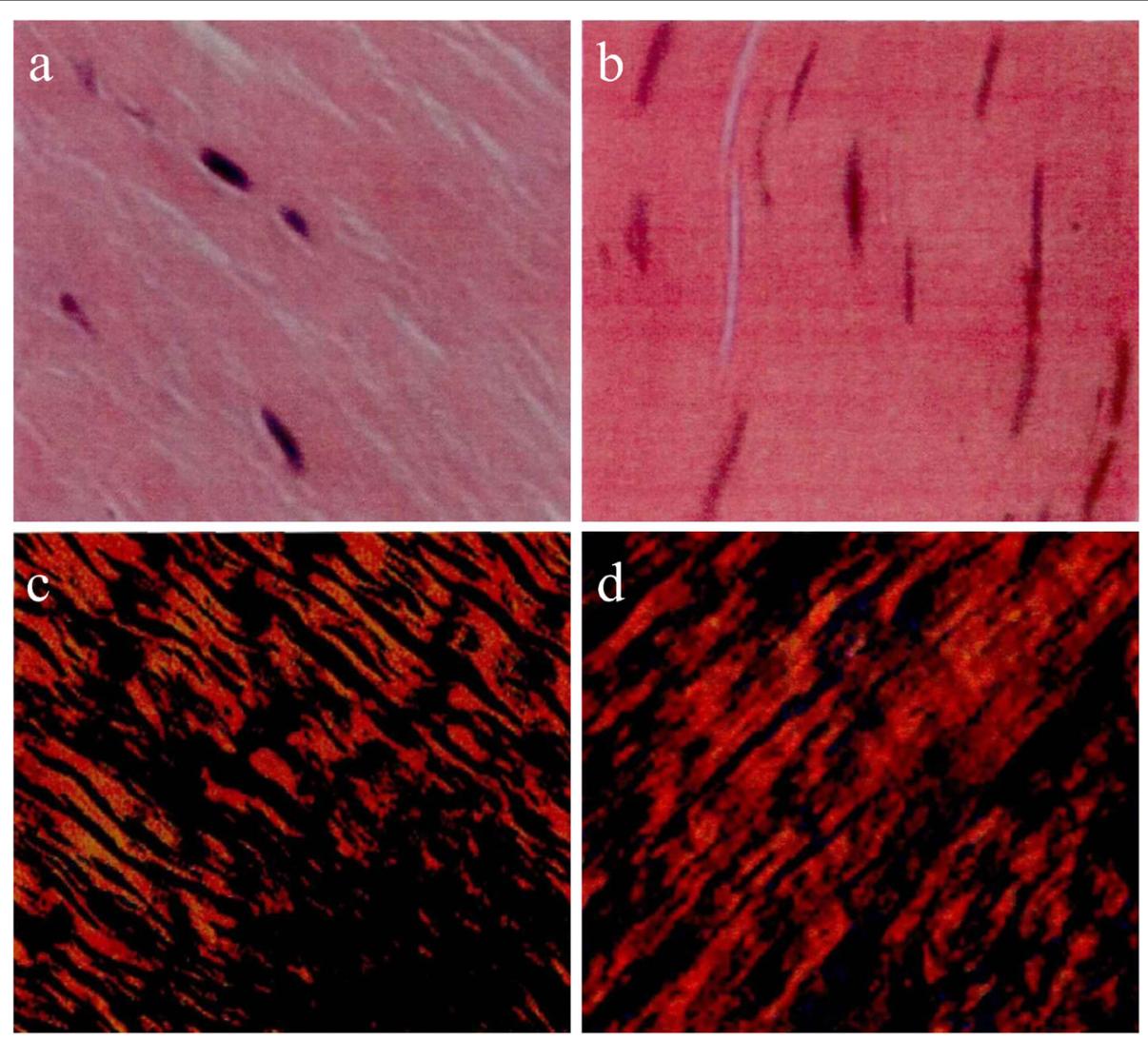

Fig. $1 \mathrm{HE}$ staining and picrosirius-polarization staining between the experimental group and the control group at $40 \mathrm{~W}$. a In the experimental group, there were some round and oval cells as well as a small number of spindle cells in the MCL at $40 \mathrm{~W}$, presenting with vertical rows, deep color, different sizes, and uneven distribution (HE staining, $\times 400)$. b In the control group, there were some spindle cells in the MCL at $40 \mathrm{~W}$, presenting with vertical rows, deep color, different sizes, and uneven distribution as well as dense extracellular collagen fibers (HE staining, $\times 400)$. c In the experimental group, obviously loose collagen fibers were seen and locally arranged irregularly at 40 W; type III collagen fibers were distributed between type I collagen fiber bundles (picrosirius-polarization staining, $\times 400$ ). $\mathbf{d}$ In the control group, collagen fibers were arranged regularly and in bundles, and type III collagen fibers were scattered inside the fiber bundles of collagen type I (picrosirius-polarization staining, $\times 400)$ 
Table 4 Relative area of type I collagen fibers and type III collagen fibers of MCL after PCL rupture in rabbits $(\bar{x} \pm s$, unit: Pixel)

\begin{tabular}{|c|c|c|c|c|}
\hline \multirow{2}{*}{$\begin{array}{l}\text { Time } \\
\text { point }\end{array}$} & \multicolumn{2}{|l|}{ Type I collagen fiber } & \multicolumn{2}{|l|}{ Type III collagen fiber } \\
\hline & Experimental group & Control group & Experimental group & Control group \\
\hline $8 W$ & $2288298 \pm 791121$ & $1965850 \pm 542089$ & $287521 \pm 85646$ & $257014 \pm 120367$ \\
\hline $16 \mathrm{~W}$ & $2457075 \pm 441482$ & $2132067 \pm 623800^{*}$ & $331327 \pm 107473$ & $258771 \pm 94562^{*}$ \\
\hline $24 W$ & $2686478 \pm 573531$ & $2286165 \pm 748951^{*}$ & $340489 \pm 119725$ & $281128 \pm 131748^{*}$ \\
\hline $40 W$ & $1896804 \pm 638037$ & $2490337 \pm 634436^{*}$ & $244548 \pm 89373$ & $287212 \pm 92497$ \\
\hline
\end{tabular}

${ }^{*} P<0.05$

between type I collagen fiber bundles, as shown in Fig. 1c. In the control group, the collagen fibers were arranged in an orderly manner, in bundles, and in the same direction. Type III collagen fibers were scattered in the interior of type I collagen fiber bundles, as shown in Fig. 1d.

\section{Comparison of type I and type III collagen fibers}

At $8 \mathrm{~W}, 16 \mathrm{~W}$, and $24 \mathrm{~W}$, the relative area of type I collagen fibers and type III collagen fibers in the experimental group was larger than that in the control group, and the difference between the experimental group and the control group at $16 \mathrm{~W}$ and $24 \mathrm{~W}$ was significant $(P$ $<0.05)$. The relative area of type I femoral fibrils in the experimental group was smaller than that in the control group, and the difference was significant $(P<0.05)$. However, the relative area of type III femoral fibrils in the experimental group was smaller than that in the control group, and the difference was not significant $(P$ $>0.05)$. The relative areas of type I collagen fibers and type III collagen fibers at each time point are shown in Table 4.

At $8 \mathrm{~W}, 16 \mathrm{~W}$, and $24 \mathrm{~W}$, the relative total area of type I and type III collagen fibers in the MCL of the experimental group was significantly larger than that of the control group $(P<0.05)$ and was significantly smaller than that of the control group at 40 weeks $(P<0.05)$ as shown in Table 5. At each time point, the ratio of type I/III collagen fibers in the MCL of the experimental group was lower than that of the control group, and there was a significant difference between the experimental group and the control group at 16, 24, and 40 weeks $(P<0.05)$ as shown in Table 6.

Table 5 Relative total area of type I and type III collagen fibers in MCL after PCL rupture in rabbits ( $\bar{x} \pm s$, unit: Pixel)

\begin{tabular}{llll}
\hline Time point & Experimental group & Control group & $P$ \\
\hline 8W & $2575819 \pm 857442$ & $2222864 \pm 624240$ & $<0.05$ \\
16W & $2788403 \pm 476859$ & $2390838 \pm 725751$ & $<0.05$ \\
24W & $3026968 \pm 674192$ & $2567293 \pm 846089$ & $<0.05$ \\
40W & $2141352 \pm 708207$ & $2777549 \pm 708652$ & $<0.05$ \\
\hline
\end{tabular}

\section{Discussion}

There are two main factors affecting the strength of the ligament under load: the shape and size of the ligament and the loading speed [19]. The larger the number of fibers in accordance with the loading direction, and the wider and thicker these fibers are, the stronger the ligament is. In the tensile test, it was found that the maximum load of the MCL of an intact PCL knee joint increased gradually with the extension of time, which increased greatly between $8 \mathrm{~W}$ and $16 \mathrm{~W}, 16 \mathrm{~W}$, and 24 W. Although the time interval was twice as long as before, the increase was relatively slow at $40 \mathrm{~W}$. Woo et al. [20] carried out mechanical tests on the MCL of rabbits and found that the maximum load of rabbits increased with age, and the male rabbits reached the plateau stage at 6 months. At $8 \mathrm{~W}, 16 \mathrm{~W}$, and $24 \mathrm{~W}$, the maximum MCL load of the PCL rupture knee joint gradually increased, and the maximum MCL load at each time point was greater than that of the intact PCL knee joint. Many studies have shown that mechanical stimulation can change cell performance through a variety of signaling pathways [21]. After removing the MCL of the rabbit, Mark implanted a stainless steel nail under its healing tissue to increase the stress when keeping it in the cage for $4 \mathrm{~W}$ [22]. After feeding for a period of time, he found that the total amount of collagen and the ratio of I/III type collagen were closer to normal than those in the natural healing group without the steel nail. Therefore, it is believed that increasing the stress could improve the histological remodeling of the ligament, i.e., the increase in the number of more longitudinally arranged collagen fibers and cells.

Similar to the tensile mechanical results, the nanoindentation test also revealed that the elastic modulus and hardness of the rabbit MCL increased with age. In addition, the elastic modulus and micro-hardness of the PCL-cut knee joint MCL at $8 \mathrm{w}, 16 \mathrm{w}$, and $24 \mathrm{w}$ were greater than those of the PCL-complete group, and there was a significant difference at $24 \mathrm{~W}$. After a rupture of the PCL, the MCL played a compensatory role by increasing the stress, and it was easier to tension or to pull more in the process of the activity. In contrast, under the condition of loaded braking, the mechanical properties will decrease. It was found that the stiffness, ultimate 
Table 6 The ratio of type I/type III collagen fibers in MCL after $\mathrm{PCL}$ rupture in rabbits $(\bar{x} \pm s)$

\begin{tabular}{llll}
\hline Time point & Experimental group & Control group & $\boldsymbol{P}$ \\
\hline $8 \mathrm{~W}$ & $8.12 \pm 2.27$ & $8.52 \pm 2.67$ & $>0.05$ \\
$16 \mathrm{~W}$ & $8.28 \pm 3.83$ & $8.80 \pm 2.43$ & $<0.05$ \\
24W & $8.37 \pm 1.86$ & $9.02 \pm 2.83$ & $<0.05$ \\
40W & $7.98 \pm 1.76$ & $9.07 \pm 1.90$ & $<0.05$ \\
\hline
\end{tabular}

load, and energy absorption of the femoral-MCL-tibia complex of rabbits decreased significantly after braking, and the elastic modulus of the MCL decreased by $50 \%$ [23]. The results of Walsh et al. [24] showed that the maturation of the structural characteristics of MCL was inhibited during the immobilization process, and the longer the immobilization time was, the more obvious the sign of structural degradation was. Therefore, it is considered that certain stress stimulation can promote the remodeling of the MCL and increase the mechanical properties to meet the functional requirements. It was also found that the elastic modulus and micro-hardness of the experimental group were significantly decreased compared with those of the control group at $40 \mathrm{~W}$.

The MCL of the rabbit knee joint was strained only during extension and excessive flexion, while the knee joint was flexed when standing still [25]. After the PCL was removed, the knee joint was not fixed, resulting in backward instability. Although rabbits can move freely, the joint load is generally physiological, which is due to the limitation of cage space and knee joint range of motion, so the degree of PCL backward displacement is less than that of severe exercise or overload. In contrast, it stimulates signal changes in cells and extracellular matrix (ECM) in the ligament, which leads to structural remodeling and functional adaptation of the ligament. With the extension of the PCL rupture time, it was found that the maximum load and micro-hardness of the experimental group were significantly reduced compared with those of the control group at $40 \mathrm{~W}$. Although PCL rupture does not cause damage in a short time, the relaxation of soft tissues increases with the extension of time, and the stress on the MCL also increases correspondingly, resulting in slow ligament injury.

Type I collagen of the ligament is composed of tightly arranged and thick collagen fibers, which can resist a high load, while type III collagen comprises small fibers with less strength than type I collagen [26]. Therefore, the histological and material mechanical properties of ligaments can be judged to a certain extent by comparing the relative amount of type I collagen and type III collagen and the ratio of type I/III collagen [27]. Amiel et al. [28] studied the MCL of 2-, 12-, and 36-month-old New Zealand white rabbits and found that with increasing rabbit age, the water content in the ligament decreased significantly, the degree of collagen crosslinking increased, and the collagen synthesis rate decreased from the highest value at 2 months to the lowest value at 36 months. The structure of the MCL in the knee joint gradually tended to mature, and the histological properties were also improved. Some studies have also confirmed that MCL cells have a good ability to synthesize collagen and to induce collagen maturation [29]. Early studies found that type III collagen was first produced in the healing process of ligament tissue and then transformed into type I collagen after a period of time. With the transformation of type III collagen to type I collagen, the tendon and ligament obtained stronger mechanical properties [30]. Busch et al. [31] found that after mechanical stimulation of patellar ligament fibroblasts, the release of type I procollagen and fibrin increased significantly after $6 \mathrm{~h}$, while after mechanical stimulation of fibroblasts for $30 \mathrm{~min}$, the release of type III procollagen increased significantly after $12 \mathrm{~h}$. The viscoelasticity of the ligament can highly adapt to knee joint function, and collagen fiber allows stretching within a certain range, but when the external force exceeds its allowable range or overloads for a long time, fibroblasts or collagen will be damaged [32].

The mechanical properties of the MCL in rabbits did not decrease significantly in the past 6 months after knee rupture but improved to some extent, which suggests that the ligament achieves functional compensation through structural remodeling. However, the maximum load, elastic modulus, and micro-hardness tended to decrease after nearly 10 months of PCL rupture. Histological observation of the MCL revealed that the number of MCL collagen fibers in the PCL rupture group was increased compared with the PCL intact group in the short term, but the ratio of type I/type III collagen fibers was different from that in the PCL intact group, so it was considered that structural remodeling did not completely normalize the ligaments. The number of MCL type I and type III collagen fibers decreased significantly at $40 \mathrm{~W}$, which also explained our previous biomechanical results.

The findings of this study have to be seen in light of some limitations. First, the bilateral knee joints of experimental animals were used as self-controls in this study. Although the control group was also treated with a sham operation, PCL disruption in the experimental group may also affect the control group, which needs to be corrected in future studies. Second, due to the lack of PCL fracture research on the MCL, the results of this study cannot be directly compared with previous studies. This aspect is not only an innovation but also a limitation of this research. Third, this study did not analyze the cartilage or perform microscopic identification of the cartilage, which made it impossible to evaluate the development of OA after PCL rupture. It is worth studying the OA process in the future. 


\section{Conclusion}

PCL ruptures do not have a large effect on the mechanical and histological properties of the MCL under shortterm physiological loading, but the histological and mechanical properties of the MCL show a significant decrease over time. Therefore, if a PCL rupture fails to effectively restore posterior stability for a long time, even with lower physiological load and limited range of motion, MCL damage can occur. This finding should be given attention in clinical practice.

\section{Abbreviations}

PCL: Posterior cruciate ligament; MCL: Medial collateral ligament; ACL: Anterior cruciate ligament; OA: Osteoarthritis; FMTC: Femur MCL tibia complex; ECM: Extracellular matrix

\section{Acknowledgements}

Not applicable.

\section{Authors' contributions}

YSL, WQX, and FY designed the study, analyzed the experiments, and wrote the paper. MH, YQH, DJY, and HFJ carried out the data collection and data analysis and revised the paper. The authors read and approved the final version of the manuscript.

\section{Funding}

This work was supported by the National Key R\&D Program of China (2019YFA0111900), National Natural Science Foundation of China (81874030, 82072506,81902274), Provincial Natural Science Foundation of Hunan (2020JJ3060), Innovation-Driven Project of Central South University (2020CX045), Provincial Clinical Medical Technology Innovation Project of Hunan (2020SK53709, 2020SK53708), the Administration of Traditional Chinese Medicine of Hunan Province (2021075), the Clinical and Rehabilitation Research Foundation of Xiangya Hospital and Weiming of Peking University (xywm2015II04), Scientific Research Project of Hunan Provincial Health and Family Planning Commission (C2017002), Wu Jieping Medical Foundation (320.6750.2020-03-14), CMA-Young and Middle-aged Doctors Outstanding Development Program--Osteoporosis Specialized Scientific Research Fund Project(G-X-2019-1107-12), and the Key program of Health Commission of Hunan Province (20201902).

\section{Availability of data and materials}

The datasets used and analyzed during the current study are available from the corresponding author on reasonable request.

\section{Declarations}

Ethics approval and consent to participate

The authors are accountable for all aspects of the work in ensuring that questions related to the accuracy or integrity of any part of the work are appropriately investigated and resolved. Experiments were performed under a project license (NO: 201908799) granted by the Ethics Committee of the Xiangya Hospital, Central South University, in compliance with guidelines for the care and use of animals.

\section{Consent for publication}

Not applicable.

\section{Competing interests}

The authors declare that they have no competing interests.

\section{Author details}

${ }^{1}$ Department of Orthopaedics, Xiangya Hospital, Central South University, 87 Xiangya Road, Changsha 410008, Hunan, China. ${ }^{2}$ National Clinical Research Center for Geriatric Disorders, Xiangya Hospital, Central South University, 87 Xiangya Road, Changsha 410008, Hunan, China.
Received: 23 January 2021 Accepted: 22 April 2021

Published online: 21 May 2021

\section{References}

1. Kennedy NI, Wijdicks CA, Goldsmith MT, Michalski MP, Devitt BM, Årøen A, et al. Kinematic analysis of the posterior cruciate ligament, part 1: the individual and collective function of the anterolateral and posteromedial bundles. Am J Sports Med. 2013;41(12):2828-38. https://doi.org/10.1177/03 63546513504287

2. Hughston JC, Bowden JA, Andrews JR, Norwood LA. Acute tears of the posterior cruciate ligament. Results of operative treatment. J Bone Joint Surg Am. 1980;62(3):438-50. https://doi.org/10.2106/00004623-19806203000014.

3. Schulz MS, Russe K, Weiler A, Eichhorn HJ, Strobel MJ. Epidemiology of posterior cruciate ligament injuries. Arch Orthop Trauma Surg. 2003;123(4): 186-91. https://doi.org/10.1007/s00402-002-0471-y.

4. Schlumberger $M$, Schuster $P$, Eichinger $M$, Mayer $P$, Mayr $R$, Immendörfer $M$, et al. Posterior cruciate ligament lesions are mainly present as combined lesions even in sports injuries. Knee Surg Sports Traumatol Arthrosc. 2020; 28(7):2091-8. https://doi.org/10.1007/s00167-020-05919-4.

5. Badri A, Gonzalez-Lomas G, Jazrawi L. Clinical and radiologic evaluation of the posterior cruciate ligament-injured knee. Curr Rev Musculoskelet Med. 2018;11(3):515-20. https://doi.org/10.1007/s12178-018-9505-0.

6. Caldas MTL, Braga GF, Mendes SL, da Silveira JM, Kopke RM. Posterior cruciate ligament injury: characteristics and associations of most frequent injuries. Rev Bras Ortop. 2013;48(5):427-31. https://doi.org/10.1 016/j.rbo.2012.09.011.

7. Jacobi M, Reischl N, Wahl P, Gautier E, Jakob RP. Acute isolated injury of the posterior cruciate ligament treated by a dynamic anterior drawer brace: a preliminary report. J Bone Joint Surg Br. 2010;92:1381-4.

8. Pierce CM, O'Brien L, Griffin LW, Laprade RF. Posterior cruciate ligament tears: functional and postoperative rehabilitation. Knee Surg Sports Traumatol Arthrosc. 2013;21(5):1071-84. https://doi.org/10.1007/s00167012-1970-1.

9. Wang D, Graziano J, Williams RJ 3rd, Jones KJ. Nonoperative treatment of PCL injuries: goals of rehabilitation and the natural history of conservative care. Curr Rev Musculoskelet Med. 2018;11(2):290-7. https://doi.org/10.1007/ s12178-018-9487-y.

10. Matava MJ, Ellis E, Gruber B. Surgical treatment of posterior cruciate ligament tears: an evolving technique. J Am Acad Orthop Surg. 2009;17(7): 435-46. https://doi.org/10.5435/00124635-200907000-00004.

11. Shelbourne KD, Benner RW, Ringenberg JD, Gray T. Optimal management of posterior cruciate ligament injuries: current perspectives. Orthop Res Rev. 2017;9:13-22. https://doi.org/10.2147/ORR.S113617.

12. Petrigliano FA, McAllister DR. Isolated posterior cruciate ligament injuries of the knee. Sports Med Arthrosc Rev. 2006;14(4):206-12. https://doi.org/10.1 097/01.jsa.0000212325.23560.d2.

13. Gao SG, Jiang W, Lei GH, Xu M, Yu F, Li KH. Effect of posterior cruciate ligament rupture on biomechanical features of the medial femoral condyle. Orthop Surg. 2011;3(3):205-10. https://doi.org/10.1111/j.17577861.2011.00138.x

14. Deng Z, Li Y, Liu H, Li K, Lei G, Lu B. Effect of posterior cruciate ligament rupture on biomechanical and histological features of lateral femoral condyle. Med Sci Monit. 2016;22:4369-79. https://doi.org/10.12 659/MSM.900502.

15. Deng $Z$, Li Y, Lin Z, Zhu Y, Zhao R. The biomechanical and histological effects of posterior cruciate ligament rupture on the medial tibial plateau. J Orthop Surg Res. 2017;12(1):48. https://doi.org/10.1186/s13018017-0551-x.

16. Deng Z, Luo W, Gao S, Liao Z, Hu Y, He H, et al. The morphology and histology study on rabbit degenerated medial meniscus after posterior cruciate ligament rupture. Biosci Rep. 2019;39(1). https://doi.org/10.1042/BSR20181843.

17. Woo SL, Orlando CA, Gomez MA, Frank CB, Akeson WH. Tensile properties of the medial collateral ligament as a function of age. J Orthop Res. 1986; 4(2):133-41. https://doi.org/10.1002/jor.1100040201.

18. Karimzadeh A, SS RK, Ayatollahi MR, Bushroa AR, Yahya MY. Assessment of nano-indentation method in mechanical characterization of heterogeneous nanocomposite materials using experimental and computational approaches. Sci Rep. 2019;9(1):15763. https://doi.org/10.1038/s41598-019-51904-4.

19. Sevick JL, Abusara Z, Andrews SH, Xu M, Khurshid S, Chatha J, et al. Fibril deformation under load of the rabbit Achilles tendon and medial collateral 
ligament femoral entheses. J Orthop Res. 2018;36(9):2506-15. https://doi. org/10.1002/jor.23912.

20. Woo SL, Ohland KJ, Weiss JA. Aging and sex-related changes in the biomechanical properties of the rabbit medial collateral ligament. Mech Ageing Dev. 1990;56(2):129-42. https://doi.org/10.1016/0047-6374(90)90004-Y.

21. Wall M, Butler D, El Haj A, Bodle JC, Loboa EG, Banes AJ. Key developments that impacted the field of mechanobiology and mechanotransduction. J Orthop Res. 2018;36(2):605-19. https://doi.org/10.1002/jor.23707.

22. Gomez MA, Woo SL, Amiel D, Harwood F, Kitabayashi L, Matyas JR. The effects of increased tension on healing medical collateral ligaments. Am J Sports Med. 1991;19(4):347-54. https//doi.org/10.1177/036354659101900405.

23. Woo SL, Gomez MA, Sites TJ, Newton PO, Orlando CA, Akeson WH. The biomechanical and morphological changes in the medial collateral ligament of the rabbit after immobilization and remobilization. J Bone Joint Surg Am. 1987:69(8):1200-11. https://doi.org/10.2106/00004623-198769080-00014.

24. Walsh S, Frank C, Shrive N, Hart D. Knee immobilization inhibits biomechanical maturation of the rabbit medial collateral ligament. Clin Orthop Relat Res. 1993:253-61.

25. Lam TC, Frank CB, Shrive NG. Changes in the cyclic and static relaxations of the rabbit medial collateral ligament complex during maturation. J Biomech. 1993;26(1):9-17. https://doi.org/10.1016/0021-9290(93)90609-I.

26. Wan C, Hao Z, Wen S. A quantitative comparison of morphological and histological characteristics of collagen in the rabbit medial collateral ligament. Ann Anat. 2013;195(6):562-9. https://doi.org/10.1016/j.aanat.2013.09.003.

27. Wan C, Hao Z, Wen S, Leng H. A quantitative study of the relationship between the distribution of different types of collagen and the mechanical behavior of rabbit medial collateral ligaments. PLoS One. 2014;9(7):e103363. https://doi.org/10.1371/journal.pone.0103363.

28. Amiel D, Kuiper SD, Wallace CD, Harwood FL, VandeBerg JS. Age-related properties of medial collateral ligament and anterior cruciate ligament: a morphologic and collagen maturation study in the rabbit. J Gerontol. 1991; 46(4):B159-65. https://doi.org/10.1093/geronj/46.4.B159.

29. Kato S, Saito M, Funasaki H, Marumo K. Distinctive collagen maturation process in fibroblasts derived from rabbit anterior cruciate ligament, medial collateral ligament, and patellar tendon in vitro. Knee Surg Sports Traumatol Arthrosc. 2015;23(5):1384-92. https://doi.org/10.1007/s00167-013-2773-8.

30. Ng GY, Oakes BW, Deacon OW, McLean ID, Eyre DR. Long-term study of the biochemistry and biomechanics of anterior cruciate ligament-patellar tendon autografts in goats. J Orthop Res. 1996;14(6):851-6. https://doi.org/1 0.1002/jor.1100140602

31. Bosch U, Zeichen J, Skutek M, Albers I, van Griensven M, Gässler N. Effect of cyclical stretch on matrix synthesis of human patellar tendon cells. Unfallchirurg. 2002;105(5):437-42. https://doi.org/10.1007/s00113-001-0373-4.

32. Henninger HB, Ellis BJ, Scott SA, Weiss JA. Contributions of elastic fibers, collagen, and extracellular matrix to the multiaxial mechanics of ligament. J Mech Behav Biomed Mater. 2019;99:118-26. https://doi.org/10.1016/j. jmbbm.2019.07.018.

\section{Publisher's Note}

Springer Nature remains neutral with regard to jurisdictional claims in published maps and institutional affiliations.

Ready to submit your research? Choose BMC and benefit from:

- fast, convenient online submission

- thorough peer review by experienced researchers in your field

- rapid publication on acceptance

- support for research data, including large and complex data types

- gold Open Access which fosters wider collaboration and increased citations

- maximum visibility for your research: over $100 \mathrm{M}$ website views per year

At BMC, research is always in progress.

Learn more biomedcentral.com/submissions 